\title{
Outbreak of West Nile virus infection in humans, Romania, July to October 2010
}

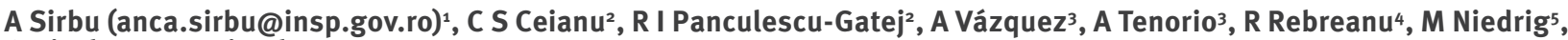
G Nicolescu ${ }^{2}$, A Pistol $^{1}$

1. National Institute of Public Health - National Centre for Surveillance and Control of Communicable Diseases, Bucharest, Romania

2. Cantacuzino National Institute for Research and Development in Microbiology and Immunology, Bucharest, Romania

3. Institute of Public Health 'Carlos III', Madrid, Spain

4. National Institute of Public Health - Regional Centre of Public Health, Cluj, Romania

5. Robert Koch Institute, Berlin, Germany

Citation style for this article:

Sirbu A, Ceianu CS, Panculescu-Gatej RI, Vázquez A, Tenorio A, Rebreanu R, Niedrig M, Nicolescu G, Pistol A. Outbreak of West Nile virus infection in humans, Romania, July to October 2010. Euro Surveill. 2011;16(2):pii=19762. Available online: $\mathrm{http}$ ://www.eurosurveillance.org/ViewArticle.aspx?Articleld=19762

Article published on 13 January 2011

A total of 57 cases of West Nile virus infection ( 54 with neuroinvasive infection and three with fever) were identified in Romania between July and October 2010. The median age of the cases was 53.4 years, with the highest incidence in the age group 60-69 years. The case fatality rate was $8.8 \%$. Cases were distributed in 19 districts in the southern, western, central and eastern parts of the country. Molecular investigation revealed lineage 2 West Nile virus, related to the Volgograd 2007 strain.

\section{Introduction}

On 28 August 2010, the National Reference Laboratory for Vector-borne Diseases in the Cantacuzino Institute in Romania reported to the National Centre for Surveillance and Control of Communicable Diseases (NCSCCD) 10 positive results for West Nile virus (WNV) in samples of patients distributed in nine different Romanian districts. Six of these 10 cases were male and four were female, with a median age of 56 years (range: 32-79 years).

Romania recorded the first large outbreak of West Nile neuroinvasive disease (WNND) in Europe in 1996, with 393 confirmed cases. This was also the first such outbreak in urban settings. Cases were confined to Bucharest, its rural surroundings and 14 districts in the Danube Plain $[1,2]$. In response to this outbreak, in 1997, the Ministry of Health set up a regional, hospitalbased surveillance system and sporadic cases were recorded every year in the districts neighbouring the Danube River [3]. In 2009, the surveillance system was extended at national level, following the confirmation of two cases of West Nile fever (WNF) in humans in the central part of Romania and the detection of WNVspecific IgG antibodies among horses in many other areas of the country.

Within the routine WNV surveillance activities in Romania, the following case definition is used for a suspected case with WNV infection: a person over 15 years of age who presents with fever and meningitis, encephalitis or meningoencephalitis between May and October and who reports a history of mosquito bites.

Two sets of samples are collected for each suspected case: for patients with acute symptoms both cerebrospinal fluid (CSF) and serum are taken. For patients in convalescence phase, a second serum sample is taken 14-21 days later. A probable or confirmed case of WNV infection is defined as a person who met the relevant clinical and the laboratory criteria for probable or confirmed cases described in the European Union case definition [4]. A suspected case is considered not to be a case if WNV-specific IgM was not detected in CSF and serum.

Data were obtained from infectious disease hospitals and reported using a standardised form containing information on symptoms, onset date and possible risk factors.

Following an outbreak of WNV infection in Greece in July to August 2010 [5], surveillance for WNND was enhanced in all districts in Romania from 12 August 2010. All districts were asked to increase their vigilance. In addition, the case definition for suspected cases used for routine surveillance was modified: a history of travel in the Danube Delta and/or in Greece was added.

\section{Outbreak description}

On 30 August 2010, after the 10 WNND cases had been reported on 28 August, the NCSCCD further reinforced the WNV surveillance activities in humans at national level and the case definition was modified once more: all persons aged over 15 years presenting with fever and meningitis or encephalitis or meningoencephalitis and clear CSF were considered suspected cases and were tested for WNV-specific antibodies. 
After a cluster of five cases was recorded on 28 August 2010 in a newly affected area in Central Transylvania (Alba district - Blaj city, Mures and Sibiu districts), active perifocal surveillance was set up locally for WNF cases as part of the enhanced surveillance: epidemiologists were involved in retroactively identifying persons who presented to general practitioners with fever and rash during August 2010. Samples from these patients were tested for the presence of WNV.

The WNV surveillance season starts every year from early May and ends on 30 October. In 2010, the surveillance season was exceptionally extended by two weeks in two places that were most affected by the outbreak (Bucharest city and Constanta district). From 10 May to 15 November 2010, a total of 170 suspected cases with WNV infection were reported in Romania. Of these, 52 were confirmed cases ( 49 with WNND and three with WNF), five were probable cases and 113 were negative for WNV.

The first confirmed WNND case had symptom onset on 4 July 2010 and the last on 11 October 2010. The distribution of the probable and confirmed cases of WNV infection by date of symptom onset is presented in Figure 1.

The first case was diagnosed retroactively, during the investigation of a cluster of unexpected deaths in Constanta district, thought to be caused by hyperthermia due to high temperatures $\left(39^{\circ} \mathrm{C}\right.$ ) in early July 2010. For the rest of the cases, most $(n=28)$ had symptom onset during the second half of August, 19 in September and only three cases had symptom onset in October (Figure 1).

Among the 57 cases, the sex ratio (male:female) was 1.7:1 (36 male:21 female). The median age was 53.4 years (age range: $12-81$ years). The highest number of cases $(n=15)$ belonged to the age group 60-69 years (Figure 2).

The incidence per age group ranged from 0.1 to 0.8 per 100,000 population, with the highest values being for the age groups $60-69$ years ( 0.8 per 100,000 population) and 70 years and above (0.5 per 100,000 population). The lowest incidence was in the age groups under 20 years and $20-29$ years (0.1 per 100,000 population).

All confirmed and probable cases were hospitalised with WNV infection (31 with meningitis, 19 with meningoencephalitis and four with encephalitis). Three had non-neuroinvasive symptoms: two had fever and maculopapular exanthema and one had prolonged febrile syndrome. Among the severe cases, eight entered into a coma. Clinical symptoms included: fever $(n=53)$, headache $(n=50)$, stiff neck $(n=42)$, shivering $(n=26)$, confusion ( $n=21)$ vomiting $(n=22)$, myalgia $(n=25)$, disorientation $(n=17)$, photophobia $(n=12)$, Kernig sign $(n=14)$, Brudzinski sign $(n=8)$, memory loss $(n=3)$, maculopapular exanthema $(n=2)$.

Five deaths were recorded among the 57 identified cases, giving a case fatality rate of $8.8 \%$. All deceased patients were aged over 65 years, and had underlying conditions (hypertension, diabetes).

Of the 57 cases, 30 lived in urban settings and 27 in rural areas, giving an urban: rural ratio of 1.1:1.

Most cases $(n=35)$ were recorded in the southern part of the country, an area known to be endemic for WNV from previous years. However, WNV infections were reported in humans in previously unaffected areas, such as districts in central Transylvania, and in the Moldavian Plateau (Figure 3).

\section{FIGURE 1}

Distribution of cases of West Nile virus infection (probable and confirmed) by date of symptom onset, Romania, July October $2010(\mathrm{n}=57)$

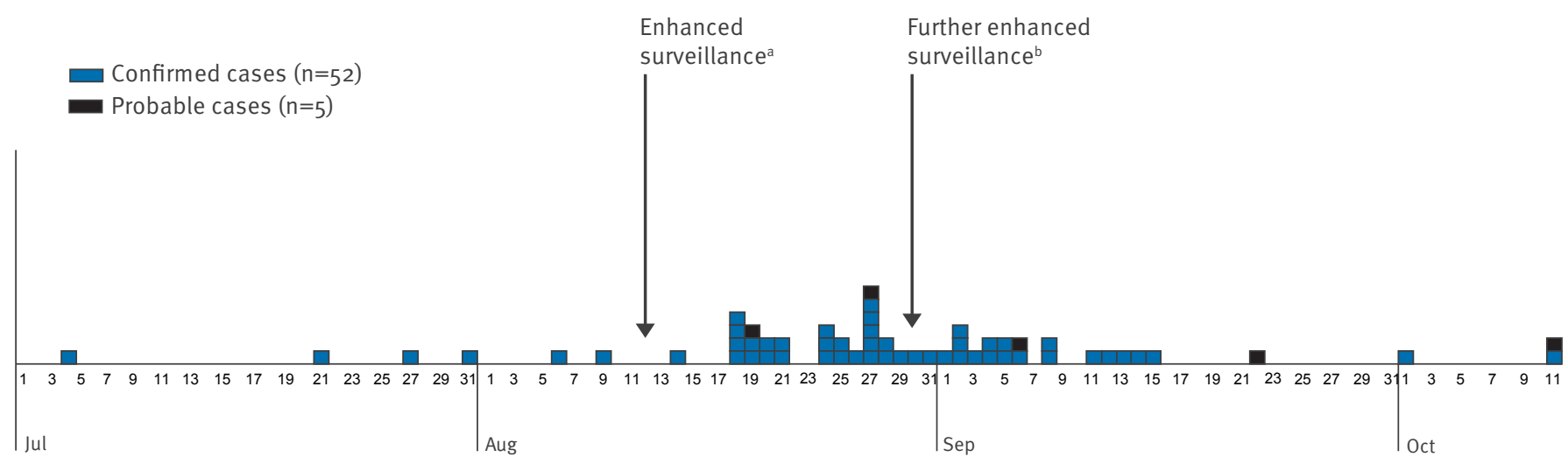

Date (2010)

a Increased vigilance and amendment of case definition.

${ }^{b}$ Reinforced surveillance activities and second amendment of the case definition. 


\section{Laboratory investigation}

Serum and CSF samples were tested for the presence of IgM and IgG antibodies specific for WNV, using a commercial enzyme-linked immunosorbent assay (ELISA) kits (Focus Technologies, USA). A total of 45 WNV neuroinvasive cases were confirmed by IgM-capture ELISA, based on the presence of WNV-specific IgM antibodies in CSF.

\section{FIGURE 2}

Incidence rate of cases of West Nile Virus infection (probable and confirmed) by age group, Romania, July October $2010(\mathrm{n}=57)$

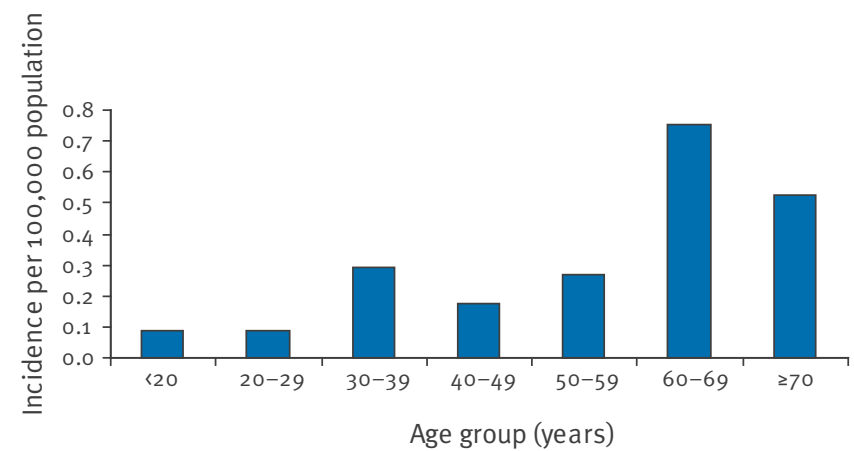

In nine cases with neurological clinical picture, CSF samples were either not available or were negative or borderline positive for WNV-specific IgM by ELISA. Serum samples from these cases were tested also by seroneutralisation assay using a lineage 1 WNV strain from Israel: four additional neuroinvasive cases were confirmed by the presence of WNV neutralising antibodies in serum, while in the other five cases, the seroneutralisation assay was negative. In the three cases with non-neuroinvasive WNV infection, the infection was confirmed by the presence of WNV neutralising antibodies in serum.

Cases from Transylvania were also tested for the presence of tick-borne encephalitis virus-specific antibodies because this virus had previously been found to be circulating in this area.

Serum and CSF samples were collected within five days from symptom onset from 16 of the 49 confirmed neuroinvasive cases; tissue samples were collected from one fatal case at the autopsy. Reverse transcription (RT) and real-time polymerase chain reaction (PCR) was used to detect the WNV genome in these samples.

\section{FIGURE 3}

Distribution of cases of West Nile virus infection (probable and confirmed) by place of exposure, Romania, July - October $2010(n=57)$

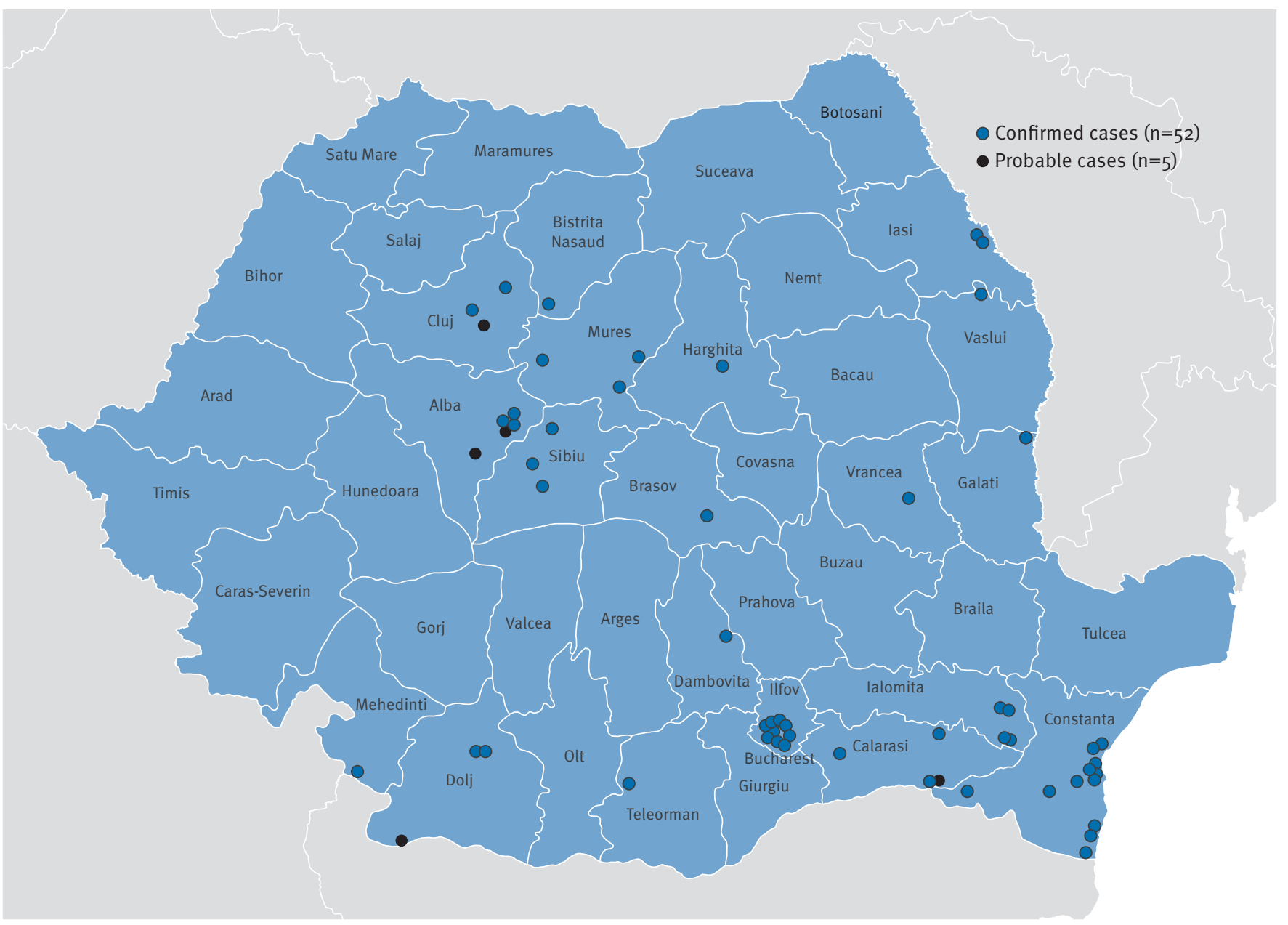


The target sequence was a conserved region of the $3^{-}$ non-coding region of WNV (Vázquez et al., unpublished data). In addition, partial sequence of the flavivirus NS5 gene was obtained following a generic RT-nestedPCR to detect flaviviruses [6]. New degenerate internal primers were designed for sequencing. Virus culture was performed for the same cases using Vero and C6-36 cells, and gave negative results after three blind passages.

Molecular investigation detected the WNV genome in the brain tissue of the fatal case, and in the serum and/ or CSF of four of the 16 cases tested. Partial sequencing of the $\mathrm{NS}_{5}$ gene was performed for only one positive (approximately 1,200 genome equivalents $/ \mathrm{ml}$ )) serum sample: analysis of 780 nucleotides of the $\mathrm{NS}_{5}$ gene demonstrated that the virus was a WNV lineage 2 strain, with $99.3 \%$ sequence identity to the virus circulating in Volgograd in 2007 (GenBank: FJ425721.1).

\section{Public health measures}

Surveillance has been gradually increased following reports of the outbreak of WNV infection in Greece and the detection of the first cases in Romania. The Ministry of Health and the regional public health authorities informed the local authorities about recommended measures for mosquito control and communicated data on the evolution of the outbreak to the general population on a weekly basis. The population was also informed about measures to reduce exposure to mosquitoes and to prevent mosquito bites.

The Ministry of Health informed the National Institute of Haematology on a daily basis about the situation of the confirmed human cases of WNV infection and about the places where they have been identified. The National Institute of Haematology deferred donations from blood donors in rural areas until 1 December 2010. Initially, donations from affected urban areas were also deferred, but at a later stage, in order to maintain a sufficient blood supply, only donors from these areas presenting with a history of fever were excluded. In addition, those who donated blood were required to report to the Blood Donation Centre any symptoms of fever in the 15 days after giving blood. Donated blood was stored and not used before the five-day period had elapsed. Donors who had spent at least one night in areas with human cases of WNV infection were excluded from donation for a period of 28 days after having left the affected area.

Veterinary doctors were informed about the occurrence of WNV infection in humans and were requested to provide information on WNV infection in animals. According to the information received from the national veterinary authority, no dead birds infected with WNV and no cases of encephalomyelitis or recent WNV infection in horses have been recorded during the outbreak in humans. Seroprevalence studies found WNV-specific antibodies in poultry from two districts in the eastern and western parts of the country. WNV-specific IgG antibodies were detected in horses from 22 districts across the country, including nine districts in which human cases of WNV infection occurred in 2010.

\section{Discussion}

With 52 confirmed cases of WNV infection widely distributed in the country, the 2010 transmission season was associated with the most important WNV infection outbreak since 1997, when the WNV surveillance system was implemented in Romania.

Weather conditions (rainfalls, high temperatures) in 2010 were favourable to the increase of mosquito populations. Culex pipiens had already been identified as the vector of WNV in the 1996 outbreak [7]. In late summer, at least in urban areas, Cx. pipiens is the main mosquito biting humans, and we may assume that in this type of environment, this species was the WNV vector in 2010 also.

A specific feature of this outbreak was its extended area in the country: cases were distributed in 19 districts, with some concentration of cases in the southeastern district of Constanta and in urban areas such as Blaj (western part) and Bucharest. Although most cases occurred in the already known endemic area in the south (in the Danube lowland and Delta neighbouring counties), in the 2010 transmission season, cases were also recorded in previously unaffected areas, from the valleys of other major rivers, known to be bird migration pathways.

Partial sequencing of the $\mathrm{NS}_{5}$ gene from a WNVpositive serum of a Bucharest resident revealed a virus strain belonging to the genetic lineage 2, highly simi$\operatorname{lar}(99.3 \%)$ to the Volgograd strain involved in the 2007 WNV outbreak in the Volga Delta area [8]. It is unsure whether the same WNV strain was involved in the outbreak beyond the Carpathian Mountains in Transylvania in 2010. Lineage 2 WNV strains were previously thought to be of low virulence. Nevertheless recent studies in South Africa suggest that lineage 2 WNV strains are a cause of neurological disease in horses and humans [9]. The WNV strain circulating in Romania from the 1996 epidemic belonged to the genetic lineage 1 [7] and was associated with a case fatality rate of $4.3 \%$ (an $8.8 \%$ rate was recorded in 2010) [1]. In conclusion, a change in the epidemiological profile of WNV infection was recorded in 2010 in Romania, with emergence of cases in previously unaffected areas in western and eastern parts of the country, and the emergence of a neuroinvasive lineage 2 WNV strain. 


\section{References}

1. Tsai TF, Popovici F, Cernescu C, Campbell GL, Nedelcu NI. West Nile encephalitis epidemic in southeastern Romania. Lancet.1998, 352(9130):767-71.

2. Han LL, Popovici F, Alexander JP Jr, Laurentia V, Tengelsen LA, Cernescu C, et al. Risk factors for West Nile virus infection and meningoencephalitis, Romania, 1996. J Infect Dis. 1999;179(1):230-3.

3. Ceianu CS, Ungureanu A, Nicolescu G, Cernescu C, Nitescu L, Tardei G, et al. West Nile virus surveillance in Romania: 19972000. Viral Immunol. 2001;14(3):251-62.

4. European Commission. Commission Decision of 28 April 2008 amending Decision 2002/253/EC laying down case definitions for reporting communicable diseases to the Community network under Decision No 2119/98/EC of the European Parliament and of the Council. 18.06.2008:L 159. Available from: http://ec.europa.eu/health/ph_threats/com/ docs/1589_2008_en.pdf

5. Papa A, Danis K, Baka A, Bakas A, Dougas G, Lytras T, et al. Ongoing outbreak of West Nile virus infections in humans in Greece, July - August 2010. Euro Surveill. 2010;15(34):pii=19644. Available from: http://www. eurosurveillance.org/ViewArticle. aspx?Articleld =19644

6. Sánchez-Seco MP, Rosario D, Domingo C, Hernandez L, Valdes K, Guzmán MG, et al. Generic RT-nested-PCR for detection of flaviviruses using degenerated primers and internal control followed by sequencing for specific identification. J Virol Methods. 2005;126:101-9.

7. Savage HM, Ceianu C, Nicolescu G, Karabatsos N, Lanciotti R, Vladimirescu A, et al. Entomologic and avian investigations of an epidemic of West Nile fever in Romania in 1996, with serologic and molecular characterization of a virus isolate from mosquitoes. Am J Trop Med Hyg, 1999;61(4): 600-11.

8. Platonov AE, Fedorova MV, Karan LS, Shopenskaya TA, Platonova OV, Zhuravlev VI. Epidemiology of West Nile infection in Volgograd, Russia, in relation to climate change and mosquito (Diptera:Culicidae) bionomics. Parasitol Res. 2008;103 Suppl 1: S45-53.

9. Venter M, Swanepoel R. West Nile virus lineage 2 as a cause of zoonotic neurological disease in humans and horses in southern Africa. Vector Borne Zoonotic Dis. 2010;10(7):659-64. 